\title{
Total and Resting Energy Expenditure in Obese Women Reduced to Ideal Body Weight
}

\author{
John M. Amatruda, ${ }^{\star *}$ Marcia C. Statt, and Stephen L. Welle ** \\ * Department of Medicine, Endocrine Metabolism Unit, and ${ }^{\ddagger}$ Department of Physiology, University of Rochester School of Medicine; \\ ${ }^{\ddagger}$ Monroe Community Hospital, Rochester, New York 14642; and ${ }^{\S}$ The Miles Research Center, West Haven, Connecticut 06511
}

\begin{abstract}
Obesity could be due to excess energy intake or decreased energy expenditure (EE). To evaluate this, we studied 18 obese females $(148 \pm 8 \%$ of ideal body weight [IBW], mean \pm SD) before and after achieving and stabilizing at IBW for at least 2 mo and a control group of 14 never obese females ( $<110 \%$ of IBW or $<30 \%$ fat ).

In the obese, reduced obese, and never obese groups, the percent of body fat was $41 \pm 4 \%, 27 \pm 4 \%$, and $25 \pm 3 \%$; total energy expenditure (TEE) was $2704 \pm 449,2473 \pm 495$, and $2259 \pm 192 \mathrm{kcal} / 24 \mathrm{~h}$; while resting metabolic rate was $1496 \pm 169,1317 \pm 159$, and $1341 \pm 103 \mathrm{kcal} / 24 \mathrm{~h}$, respectively. 15 obese subjects who withdrew from the study had a mean initial body composition and EE similar to the subjects who were successful in achieving IBW. In 10 subjects followed for at least one year after stabilizing at IBW there was no significant relationship between the deviation from predicted TEE at IBW and weight regain.

These studies indicate that, in a genetically heterogeneous female population, neither the propensity to become obese nor to maintain the obese state are due to an inherent metabolic abnormality characterized by a low EE. (J. Clin. Invest. 1993. 92:1236-1242.) Key words: obesity • resting metabolic rate • total energy expenditure $\bullet$ ideal body weight $\bullet$ body composition
\end{abstract}

\section{Introduction}

Obesity is a chronic metabolic disorder affecting approximately $26 \%$ of the American population (1) and characterized by an increase in body fat and the propensity to numerous obesity related illnesses, including hypertension, type II diabetes, cardiovascular and pulmonary disease, gallbladder disease, some forms of cancer, and other disorders (1-3). The exact etiology of obesity is unknown; however, obesity results from positive energy balance, i.e., energy intake exceeds energy expenditure. A person might become obese with a "normal" energy expenditure if intake is excessive or with "normal" energy intake if energy expenditure is subnormal.

A low energy expenditure could be due to metabolic or hormonal abnormalities that are inherited (4-8). Indeed, obesity tends to run in families $(4,5)$, and evidence for a significant genetic influence on obesity comes from studies of adop-

Address correspondence to John M. Amatruda, M.D., Miles Research Center, 400 Morgan Lane, West Haven, CT 06516-4175.

Received for publication 21 December 1992 and in revised form 22 April 1993.

J. Clin. Invest.

(c) The American Society for Clinical Investigation, Inc.

0021-9738/93/09/1236/07 $\$ 2.00$

Volume 92, September 1993, 1236-1242 tees in Denmark (6) and twins reared in separate families in Sweden (7). Metabolic rate may also have a significant genetic component $(9,10)$, and a low resting metabolic rate $(R M R)^{1}$ or total energy expenditure (TEE) is associated with an increased risk of gaining weight in southwestern American Indians (11). In addition, several studies suggest that reduced obese individuals have decreased energy expenditure, which might predispose them to gain weight or regain lost weight (12-19). Others have found energy expenditure to be normal in reduced obese individuals (20-24). These studies are generally flawed by one or more methodological problems, including the methods used to measure metabolic rate, or the failure to measure metabolic rate, to evaluate patients at ideal body weight, to measure body composition and total energy expenditure under free living conditions, or to use prospective data. Our study was designed to overcome these methodological problems and to determine in a prospective fashion whether a genetically diverse group of formerly obese women reduced to ideal body weight has a reduced energy expenditure that might have predisposed them to become obese originally or regain the lost weight. The data indicate that these reduced obese women at ideal body weight have normal resting metabolic rate and total energy expenditure, and that those individuals who were unsuccessful in achieving ideal weight had normal or elevated energy expenditures. These data indicate that excessive energy intake rather than reduced energy expenditure is etiologic in obesity.

\section{Methods}

Subjects. The 33 obese and 14 nonobese subjects accepted into the study were healthy, nondiabetic, nonpregnant, nonsmoking, premenopausal women with normal menstrual cycles. Five obese subjects were black. Two of the black subjects were successful and three were unsuccessful at achieving ideal body weight. All subjects had normal glucose tolerance (25) and no known family history of diabetes. The lean control women ( $<30 \%$ fat by ${ }^{40} \mathrm{~K}$ or $<110 \%$ of ideal body weight, calculated by assuming that the ideal body mass index [BMI] is 21) and the obese women before weight loss were instructed to maintain their usual level of activity during the measurement of total energy expenditure. The obese women when studied after weight loss were instructed to maintain a level of activity equal to that of the first energy expenditure study. The obese subjects at entry were $135-185 \%$ of the ideal BMI of 21. This degree of obesity was chosen because it represents a modest degree of obesity that is prevalent and because weight loss to ideal body weight is achievable, although none of the five women who were initially more than $161 \%$ of ideal weight achieved ideal weight.

The normal weight women were paid to participate in the study. Included in this study are 18 obese women who were successful at

1. Abbreviations used in this paper: $\mathrm{ABEE}$, above basal energy expenditure; BMI, body mass index; EE, energy expenditure; IBW, ideal body weight; LBM, lean body mass; RMR, resting metabolic rate; TEE, total energy expenditure. 
achieving and stabilizing at ideal body weight and 15 obese women who were unsuccessful. All volunteers gave verbal and written consent after all procedures were explained orally and in writing. The project was approved by the University of Rochester Research Subjects Review Board.

Weight loss protocol. Obese subjects were entered into a weight loss program that consisted of a $420-800 \mathrm{kcal} / \mathrm{d}$ formula diet until they achieved a weight of $120 \%$ above ideal body weight as determined from Metropolitan Life Insurance tables. Every sixth week they consumed a minimum of 800 calories per day. At $120 \%$ of IBW all subjects were placed on an 800-1200 calorie-per-day diet until they were less than $30 \%$ fat as determined by ${ }^{40} \mathrm{~K}$ measurement or until they were less than $110 \%$ of IBW. All subjects were seen weekly at the Clinical Research Center for a medical evaluation and to attend a behavioral modification class. All diets were prescribed by the CRC dietician to insure nutritional adequacy. Exercise was encouraged, but there were no specific exercise plans or classes. Once the weight loss goal was achieved, subjects entered a weight maintenance phase for a minimum of $2 \mathrm{mo}$ and consumed a diet containing approximately 55\% carbohydrate, $30 \%$ fat, and $13 \%$ protein.

Total energy expenditure (TEE). TEE was determined by the ${ }^{2} \mathrm{H}_{2}{ }^{18} \mathrm{O}$ method (26), during a 2-wk period starting $5 \mathrm{~d}$ after the start of the menstrual period. This method is based on the principle that $\mathrm{CO}_{2}$ production is equal to the difference between ${ }^{2} \mathrm{H}_{2} \mathrm{O}$ turnover and $\mathrm{H}_{2}{ }^{18} \mathrm{O}$ turnover, times total body water after correction for isotopic fractionation. The amount of ${ }^{2} \mathrm{H}_{2}{ }^{18} \mathrm{O}$ administered, the collection and analysis of samples, and the calculation of TEE are described in detail in a previous publication that included many of the obese, and control, never obese subjects (27). A two-point urine collection method was used, which has been validated (28). The major sources of error in estimating TEE using this method are the uncertainties about what portion of water losses are fractionated and the mean respiratory quotient during the period of measurement. We used a formula (29) that minimizes errors in subjects whose actual $\mathrm{CO}_{2}$ production was measured in an indirect calorimetry chamber. A $10 \%$ error in the portion of water losses that are fractionated would lead to an error of approximately $2.5 \%$ in the calculated energy expenditure (30). Uncertainty about the actual respiratory quotient should not cause an error greater than $3 \%$ when a value of 0.85 is assumed (30), except in subjects consuming a large amount of alcohol or a very unusual diet. Reduced obese women were studied after weight loss only if they achieved the weight loss goal.

$R M R$. RMR was measured on two consecutive days after overnight fasting in the University of Rochester Clinical Research Center (CRC). An open-circuit ventilated-mask indirect calorimeter was used (31). The mean value of the two determinations was used in the calculations. RMR determinations and body composition studies were completed within $1 \mathrm{mo}$ of the end of the ${ }^{2} \mathrm{H}_{2}{ }^{18} \mathrm{O}$ study, usually sooner.

Body composition. Weight was determined to the nearest $10 \mathrm{~g}$ on the first and last day of the energy expenditure measurement. Lean body mass was calculated as total body water (mean of values determined at the beginning and end of the ${ }^{2} \mathrm{H}_{2}{ }^{18} \mathrm{O}$ study) divided by 0.73 . Lean body mass also was determined in duplicate by ${ }^{40} \mathrm{~K}$ counting (32) following the ${ }^{2} \mathrm{H}_{2}{ }^{18} \mathrm{O}$ study and at various times during weight loss to determine if the subjects had achieved ideal body weight. We assumed that the $\mathrm{K}$ content of the fat-free body was $64.2 \mathrm{mmol} / \mathrm{kg} \mathrm{(32)}$.

Data analysis. Data analysis was performed using BMDP Statistical Software (33). Unpaired $t$ tests were used to compare mean values between groups, and paired $t$ tests were used to examine changes after weight loss. Stepwise multiple regression was used to generate the least squares linear multiple regression equation for predicting RMR and TEE. The data of all 47 subjects (only pre-weight loss data of obese subjects) were used to generate this equation.

\section{Results}

The anthropometric characteristics and energy expenditure of the 14 control and 18 obese subjects before and after reducing to ideal body weight are shown in Table I. Compared with the normal weight group, the obese group weighed $44 \%$ more, had a $14 \%$ increase in mean lean body mass (mean values determined from ${ }^{40} \mathrm{~K}$ and total body water), a $64 \%$ increase in adiposity, a mean increase in resting metabolic rate of $12 \%$, and a mean increase in total energy expenditure of $20 \%$. Thus, as we have previously shown (27), these obese women had higher resting and total expenditures than lean women. After adjustment of total energy expenditure for weight and resting metabolic rate for lean body mass by analysis of covariance, there was no significant difference in energy expenditure between the normal weight and obese women. In obese and lean individuals the total energy expenditure is 1.81 and $1.68 \times$ the resting metabolic rate, respectively.

The anthropometric characteristics and energy expenditure of the reduced obese subjects are also shown in Table I, and the weight loss curves for these subjects are shown in Fig. 1. The time to reach and stabilize at ideal body weight was $32-48 \mathrm{wk}$ (Fig. 1). Reduced obese subjects had significantly lower weight, lean body mass (LBM), and percent fat than they had before weight reduction (Table I, $P<0.001$ ). RMR was also significantly less than it was before weight loss $(P<0.001)$. However, the decrease in TEE $(231 \mathrm{kcal} / 24 \mathrm{~h})$ with weight loss was not statistically significant $(P=0.06)$. Compared with lean control women, the reduced obese subjects were significantly older, but there were no significant differences in body weight, LBM, percent fat, RMR, or TEE.

Figs. 2 and 3 illustrate the relationships between energy expenditure and LBM and weight in obese, reduced obese, and normal weight subjects. As with previous analyses (27), in multiple linear regression the standard error of the estimate for

Table I. Body Composition and Energy Expenditure in Control, Obese, and Reduced Obese Subjects

\begin{tabular}{cccc}
\hline & $\begin{array}{c}\text { Control } \\
(n=14)\end{array}$ & $\begin{array}{c}\text { Obese before wt loss } \\
(n=18)\end{array}$ & $\begin{array}{c}\text { Reduced obese } \\
(n=18)\end{array}$ \\
\hline Age & $34.0 \pm 6.3$ & $39.5 \pm 5.2^{*}$ & $40.5 \pm 5.2^{* \ddagger}$ \\
$(\mathrm{yr})$ & $(21-45)$ & $(31-51)$ & $(32-52)$ \\
$\mathrm{Wt}$ & $58.2 \pm 5.7$ & $83.7 \pm 8.5^{*}$ & $61.7 \pm 5.4^{\ddagger}$ \\
$(\mathrm{kg})$ & $(43.4-65.4)$ & $(64.6-97.0)$ & $(56.4-71.9)$ \\
$\mathrm{Ht}$ & $166 \pm 6$ & $164 \pm 6$ & $164 \pm 6$ \\
$(\mathrm{~cm})$ & $(154-178)$ & $(151-176)$ & $(151-176)$ \\
$\mathrm{IBW}$ & $100 \pm 5$ & $148 \pm 8^{*}$ & $109 \pm 5^{* \ddagger}$ \\
$(\%)$ & $(87-109)$ & $(135-161)$ & $(100-116)$ \\
$\mathrm{LBM}$ & $45.5 \pm 4.4$ & $52.3 \pm 5.7^{*}$ & $46.8 \pm 4.9^{\ddagger}$ \\
$\left({ }^{40} \mathrm{~K}\right)$ & $(34.2-51.8)$ & $(43.7-61.8)$ & $(39.5-54.7)$ \\
$\mathrm{LBM}$ & $41.0 \pm 3.1$ & $46.2 \pm 4.0^{*}$ & $43.0 \pm 4.0^{\ddagger}$ \\
$\left(\mathrm{H}{ }_{2}{ }^{18} \mathrm{O}\right)$ & $(34.2-46.2)$ & $(40.1-53.4)$ & $(36.4-50.0)$ \\
Fat & $25 \pm 3$ & $41 \pm 4^{*}$ & $27 \pm 4^{\ddagger}$ \\
$(\%)$ & $(21-30)$ & $(33-47)$ & $(20-36)$ \\
$\mathrm{RMR}$ & $1341 \pm 103$ & $1496 \pm 169^{*}$ & $1317 \pm 159^{\ddagger}$ \\
$(\mathrm{kcal} / 24 \mathrm{~h})$ & $(1138-1540)$ & $(1259-1848)$ & $(1082-1531)$ \\
TEE & $2259 \pm 192$ & $2704 \pm 449^{*}$ & $2473 \pm 495^{\S}$ \\
$(\mathrm{kcal} / 24 \mathrm{~h})$ & $(1895-2643)$ & $(1818-3944)$ & $(1587-3131)$ \\
$\mathrm{ABEE}$ & $918 \pm 213$ & $1208 \pm 359^{*}$ & $1156 \pm 406^{*}$ \\
$(\mathrm{kcal} / 24 \mathrm{~h})$ & $(537-1193)$ & $(559-2096)$ & $(370-1811)$ \\
& & & \\
\hline
\end{tabular}

Mean $\pm \mathrm{SD} /($ range)

${ }^{*} P<0.05$ compared with control group. ${ }^{\ddagger} P<0.001$ compared with before weight loss. ${ }^{\S} P=0.06$ compared with before weight loss. 


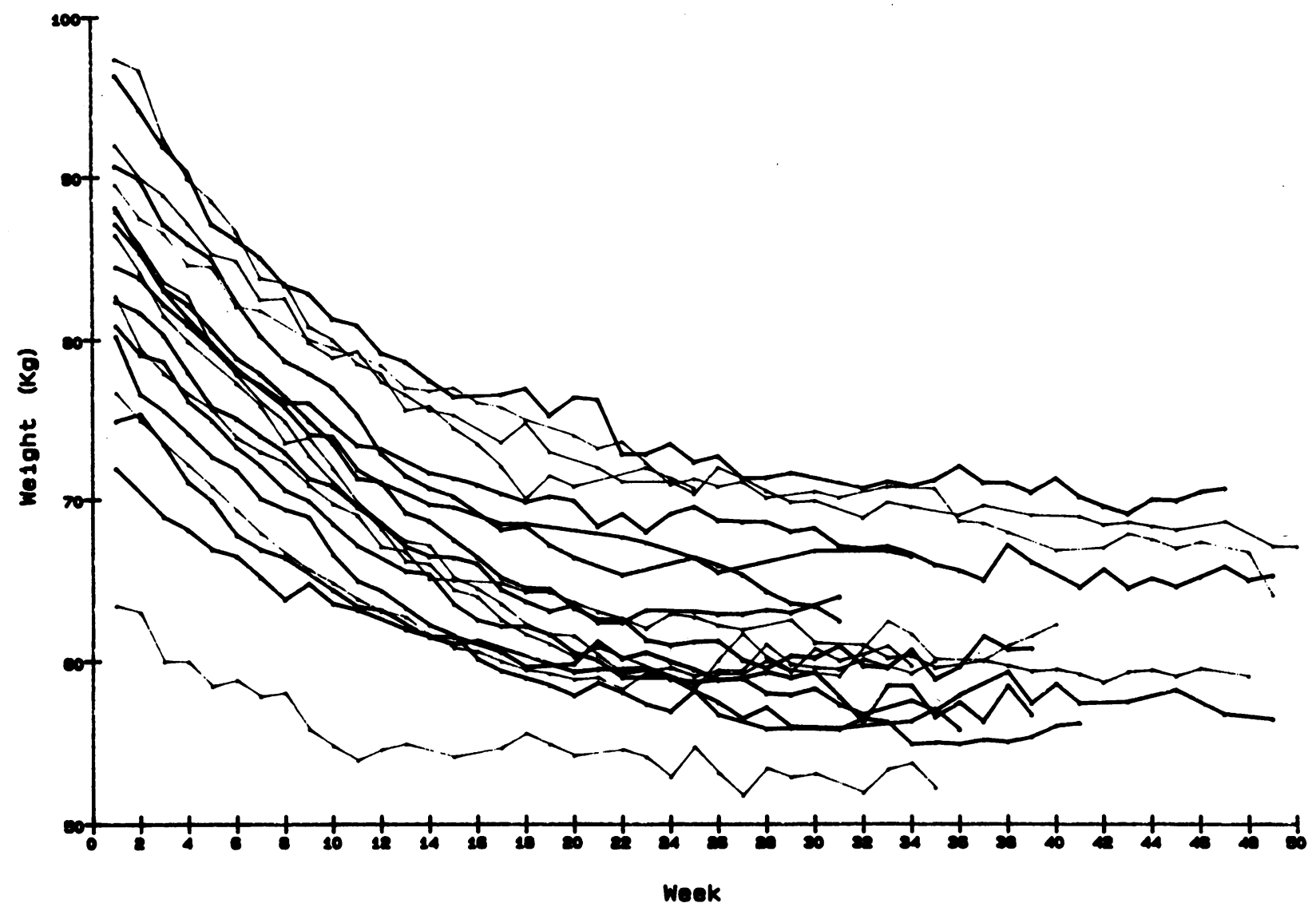

Figure 1. Weight-loss curves for the 18 obese subjects who were successful in achieving and stabilizing at ideal body weight.

TEE after entering LBM and fat is slightly greater than weight alone, and therefore LBM and fat are not included in the predictive equations for TEE. Based on the best fit multiple linear regression equations from the 14 lean women and the baseline
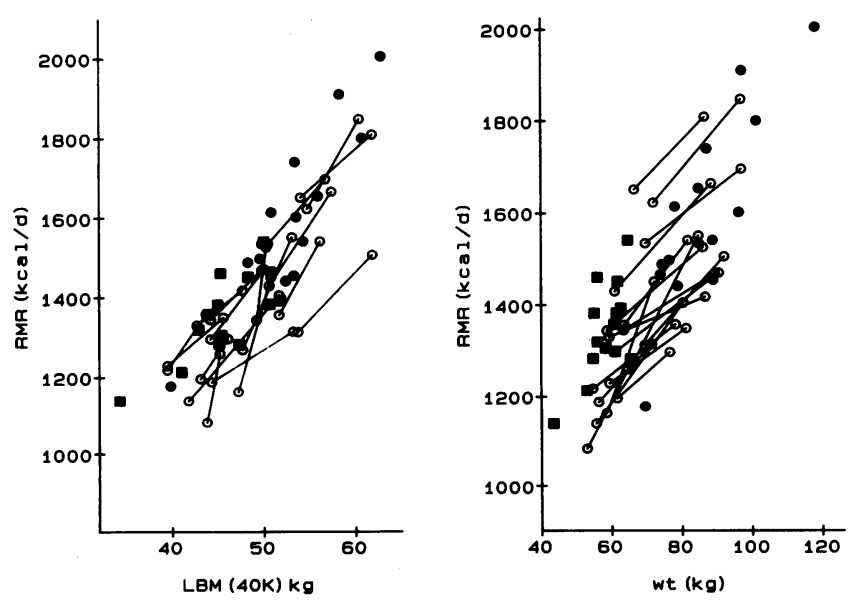

Figure 2. Resting metabolic rate as a function of lean body mass and body weight in 14 lean (squares), 33 obese (closed and open circles), and 18 reduced obese (open circles) subjects. The closed circles are obese subjects ( $n=15$ ) who were unsuccessful at achieving ideal body weight. The lines connect the obese subjects (open circles) to themselves after reducing and stabilizing at ideal body weight $(n=18)$. Lean body mass was determined by ${ }^{40} \mathrm{~K}$ counting. The data for 26 obese and 12 lean subjects have been previously published (27). data of the obese women, the reduced obese subjects had a mean TEE significantly higher than predicted (Table II), while RMR was similar to the predicted value (Table II). The difference between the observed and the predicted RMR ranged from -189 to $+162 \mathrm{kcal} / 24 \mathrm{~h}$, while the difference between the observed and predicted TEE ranged from -541 to $+831 \mathrm{kcal} /$ $24 \mathrm{~h}$. The $95 \%$ confidence intervals for the difference between the means of the reduced obese and never obese control groups are -125 to $+75 \mathrm{kcal} / 24 \mathrm{~h}$ for $\mathrm{RMR}$ and -51 to $+479 \mathrm{kcal} / 24$
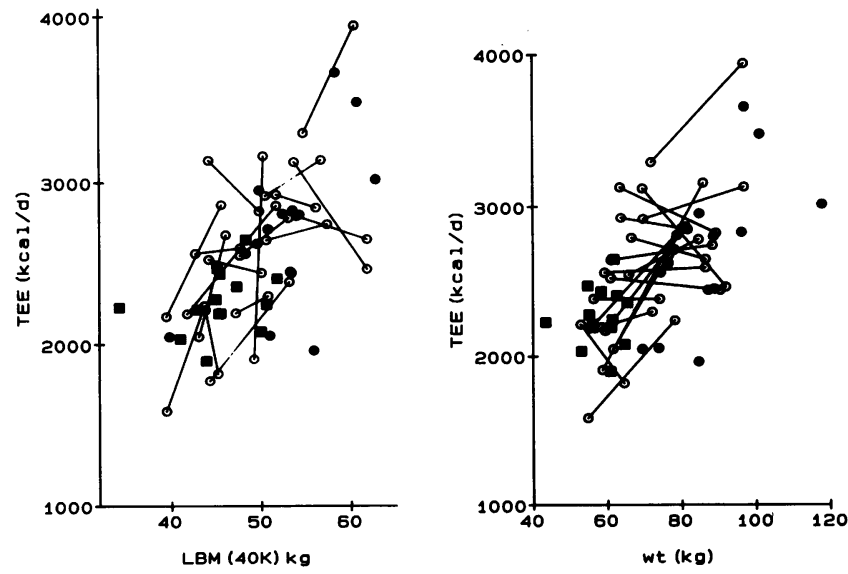

Figure 3. Total energy expenditure as a function of lean body mass and body weight in 14 lean, 33 obese, and 18 reduced obese subjects. The symbols are the same as in Fig. 2. 
Table II. Observed and Predicted Energy Expenditure of Reduced Obese Subjects

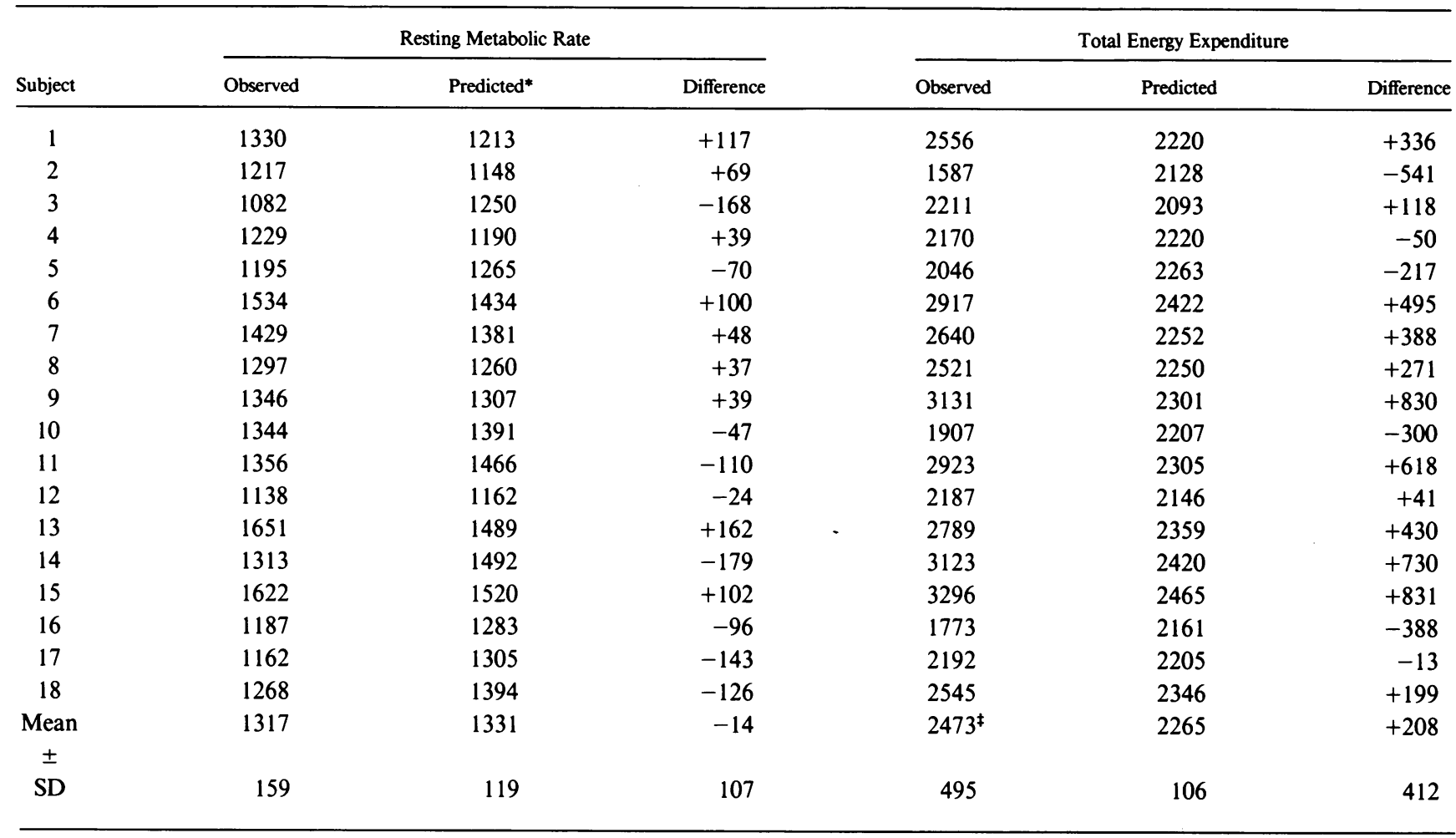

* Predicted according to the following equation based on multiple regression of the 14 control and 33 obese subjects before weight loss who participated in the study. RMR $(\mathrm{kcal} / 24 \mathrm{~h})=402+22.4 \mathrm{LBM}(\mathrm{kg})+4.2 \mathrm{FAT}(\mathrm{kg})-4.5 \mathrm{age}(\mathrm{yr}) . \mathrm{TEE}(\mathrm{kcal} / 24 \mathrm{~h})=1056+19.6 \mathrm{wt}(\mathrm{kg}) .{ }^{\ddagger} P$ $<0.05$ compared with predicted value.

$\mathrm{h}$ for TEE. The corresponding $95 \%$ confidence intervals for the difference between the observed and the predicted means for reduced obese subjects are -67 to $+39 \mathrm{kcal} / 24 \mathrm{~h}$ for $\mathrm{RMR}$ and +3 to $+413 \mathrm{kcal} / 24 \mathrm{~h}$ for TEE.

We also calculated the above basal energy expenditure $(\mathrm{ABEE}=\mathrm{TEE}-\mathrm{RMR})$, which is an index of energy used for physical activity and the thermic effect of food. As shown in Table I, ABEE was higher in obese subjects than lean control as we previously reported (27). After weight loss the ABEE did not decrease significantly and remained $26 \%$ higher in the reduced obese group than in the lean group.

Since only 18 of the 33 obese women who entered the study achieved and maintained IBW, we compared the baseline characteristics of the successful and unsuccessful women to determine if those who were unsuccessful had a low RMR or TEE. As shown in Table III, the women who were unsuccessful were younger. All other characteristics including percent fat, LBM, RMR, and TEE were similar in the two groups.

Finally, we evaluated whether weight regain in the reduced obese women is related to the deviation from the predicted normal RMR or TEE. 10 of the reduced obese women were evaluated at least $1 \mathrm{yr}$ after achieving IBW (18-34 mo). The mean weight gain was $14.5 \pm 6.1$ (SD) $\mathrm{kg}$, which represents $58 \pm 23 \%$ of the weight lost during the study. In these women RMR and TEE were not significantly different than predicted normal values. RMR and TEE were $+3 \pm 61 \mathrm{kcal} / \mathrm{d}$ and $+215 \pm 424 \mathrm{kcal} / \mathrm{d}$, respectively, compared with predicted normal values. The amount of weight regained correlated highly with the number of months to followup $(r=0.82, P<0.01)$. Surprisingly there was a positive correlation between RMR (deviation from predicted normal value) at ideal body weight and weight regained in $\mathrm{kg}(r=0.66, P<0.05)$, but there was no relationship between TEE (deviation from predicted normal values) at IBW and weight regain $(r=0.28, P>0.20)$. When adjusting for the time elapsed before subjects were reweighed, all relationships were nonsignificant.

\section{Discussion}

Because of the importance of obesity as a chronic metabolic disorder, its etiology has been extensively investigated. Most data suggest that there is an inherited component to obesity although the inherited trait is unknown (4-8). Several studies have suggested that metabolic rate may be the inherited trait (9-10), and it has been estimated that after adjusting resting metabolic rate for fat free mass, age, and gender, $40 \%$ of the remaining variance is explained by genetic factors (9). Another study estimated that $25 \%$ of the variance in fatness was due to genetic transmission (4). Similar heritability estimates were made for the increase in energy expenditure associated with meals and low intensity exercise (10). A heritable component of metabolic rate is further supported by the observation that overfed twins tend to gain similar amounts of weight (8). These observations are not surprising since RMR is closely related to LBM (27) and identical twins have similar body composition (34). Nevertheless, many individuals maintain a desirable weight even though their metabolic rates (RMR and TEE) are less than the metabolic rates of those who become obese (Figs. 2 and 3) (11,35). Studies in southwestern American Indians, however, tend to confirm the hypotheses that met- 
Table III. Baseline Characteristics of 18 Reduced Obese Subjects and 15 Subjects Who Did Not Complete the Weight Loss Program

\begin{tabular}{lcc}
\hline & $\begin{array}{c}\text { Completed weight } \\
\text { loss program } \\
(n=18)\end{array}$ & $\begin{array}{c}\text { Did not complete weight } \\
\text { loss program } \\
(n=15)\end{array}$ \\
\hline Age (yr) & $39.5 \pm 5.2$ & $32.7 \pm 6.4^{*}$ \\
& $(31-51)$ & $(21-47)$ \\
Ht $(\mathrm{cm})$ & $164.0 \pm 6.1$ & $163.4 \pm 7.0$ \\
& $(151-176)$ & $(147-174)$ \\
Weight $(\mathrm{kg})$ & $83.7 \pm 8.5$ & $86.5 \pm 12.7$ \\
& $(64.6-97)$ & $(69.5-117.9)$ \\
IBW $(\%)^{\ddagger}$ & $148 \pm 8$ & $154 \pm 15$ \\
& $(136-161)$ & $(135-185)$ \\
LBM $\left({ }^{40} \mathrm{~K}\right)$ & $52.3 \pm 5.7$ & $52.9 \pm 5.5$ \\
& $(43.7-61.8)$ & $(39.8-62.8)$ \\
LBM $\left(\mathrm{H}_{2}{ }^{18} \mathrm{O}\right)$ & $46.2 \pm 4.0$ & $46.1 \pm 6.1$ \\
& $(40.1-53.4)$ & $(33.6-55.9)$ \\
FAT $(\%)$ & $41 \pm 4$ & $43 \pm 4$ \\
& $(33-47)$ & $(37-49)$ \\
RMR $(\mathrm{kcal} / 24 \mathrm{~h})$ & $1496 \pm 169$ & $1595 \pm 207$ \\
& $(1259-1848)$ & $(1177-2005)$ \\
TEE $(\mathrm{kcal} / 24 \mathrm{~h})$ & $2704 \pm 449$ & $2691 \pm 484$ \\
& $(1818-3944)$ & $(1963-3661)$ \\
& &
\end{tabular}

Mean $\pm \mathrm{SD} /($ range $)$

${ }^{*} P<0.01$ by unpaired $t$ test. ${ }^{\ddagger}$ Based on IBW $=$ BMI of 21.0 .

abolic rate is familial and those with lower resting metabolic rates tend to gain more weight than those with higher resting metabolic rates (11). In a study of free living energy expenditure of infants born to lean and obese mothers, none of the infants born to lean mothers became obese in the first year of life whereas $50 \%$ of the infants born to overweight mothers became obese (35). The mean total energy expenditure of the infants who later became obese was $20 \%$ lower than that of the other groups. Only six overweight infants were studied and only three of them remained overweight at one year of age. In another study of children 4-5 yr old, it was found that the average resting metabolic rate and estimated total energy expenditure of those with an obese parent was $16 \%$ and $22 \%$ lower, respectively, than that of children whose parents had never been obese (36).

Other studies have evaluated the possible role of low energy expenditure in the development of obesity by studying reduced obese subjects, assuming that their metabolic rate reverts to its preobese condition when weight is normalized. Obese individuals have higher energy expenditures than lean individuals (27), and energy expenditure declines during weight loss in obese patients (12-24). There is extremely little information however, regarding the energy expenditure of obese subjects who were reduced to and stabilized at a normal body weight. One group evaluated reduced obese subjects and normal weight controls using a respiration chamber at three levels of activity $(16,18)$. At all levels of activity, the reduced obese women had metabolic rates about $15 \%$ lower than the normal weight women $(16,18)$. Another study did not confirm these results (19). Other investigators have evaluated reduced obese subjects who were still overweight after weight loss (12-15, 17). These studies suffer from problems such as the failure to measure body composition, the failure to accurately measure energy expenditure, and the use of cross-sectional data rather than longitudinal data. Other studies have suggested that following weight loss there is a reduced energy expenditure due to decreased dietary or activity related thermogenesis $(12,37)$. The decreased energy expenditure of physical activity could be due to a decrease in body weight alone (27). In contrast to these studies, several studies have shown normal total energy expenditure and resting metabolic rate in reduced obese individuals (20-24). Most recently Astrup et al. (38) used a metabolic chamber to study the TEE of eight women before and after weight normalization and found a higher energy expenditure in the postobese group.

Since it is difficult to study weight gain in a prospective fashion, we elected to study obese individuals belonging to a genetically heterogeneous population before and after weight loss and stabilization at ideal body weight. If reduced obese individuals have a lower metabolic rate than never obese control subjects, this could explain why they were obese and why they may have a greater propensity to regain weight. Previous data from our laboratory indicated that resting metabolic rate is closely correlated with lean body mass and total energy expenditure with body weight (27). Our current data confirms these findings and indicates that metabolic rate decreases with weight reduction in conjunction with decreases in lean body mass and that total energy expenditure decreases in conjunction with decreases in total weight (Table I, Figs. 2 and 3). Although the decrease in total energy expenditure associated with weight loss was not significant in this group $(P=0.06)$, the change in TEE per $\mathrm{kg}$ weight change $(10.5 \mathrm{kcal} / \mathrm{d}$ per $\mathrm{kg})$ included the value obtained by the cross-sectional data (19.6 $\mathrm{kcal} / \mathrm{d}$ per $\mathrm{kg}$ ). The reduced obese women stabilized at ideal body weight and the never obese control group had similar lean body mass, percent fat and RMR (Table I). The reduced obese women actually had a greater mean above basal energy expenditure than the control group, and their TEE tended to be greater than predicted. This suggests that activity was greater in reduced obese subjects. The clearly normal RMR, however, suggests that an inherent metabolic abnormality leading to a low metabolic rate is unlikely. The conclusion drawn from these data is that obese subjects reduced and stabilized at ideal body weight have normal energy expenditure and thus would not be expected to become obese if they had a normal energy intake. This conclusion was confirmed by analysis of covariance. Neither the RMR or TEE of the reduced obese individuals when adjusted for LBM, fat, and age, were significantly different in the control $(\mathrm{RMR}=1371 \pm 28, \mathrm{TEE}=2333 \pm 100$ $\mathrm{kcal} / 24 \mathrm{~h})$ and reduced obese $(1295 \pm 24$, TEE $=2416 \pm 86$ $\mathrm{kcal} / 24 \mathrm{~h}$ ) subjects.

The advantage of our study over those previously published lies in the fact that it is prospective, that both resting energy expenditure and total energy expenditure in a free living environment were measured, body composition was assessed by two independent measures, and that subjects were reduced to ideal body weight and stabilized for at least 2 mo before reassessing energy expenditure and body composition. Thus, any effects of weight loss itself on these parameters would be minimized.

In studies evaluating metabolic rate in reduced obese subjects it is imperative that body composition be assessed and be comparable to the control group which has never been obese. Despite using very low energy diets to initiate weight loss, our 
weight loss protocol did not lead to excessive losses of lean body mass. In fact, the reduced obese group had a similar percentage of fat as the never obese group, yet lean body mass was slightly but not significantly greater (Table I). Thus, ideal body weight with normal body composition is achievable with such a weight loss protocol.

A possible confounding factor in our data is the fact that the reduced obese group was significantly older than the never obese group. At entry into the study, the obese group and the never obese group were similar in age. However, because those who withdrew from the study were younger than those who completed the study (Table III), the average age of the reduced obese group was greater than the obese group that entered the study and the never obese group. This age difference between the reduced obese and never obese groups, while significant, would not be expected to affect our conclusions since by multiple linear regression age has no effect on TEE over the range of ages of the subjects in our study (data not shown). RMR declined slightly with age after adjusting for body composition, but this would tend to reduce rather than increase the RMR of the reduced obese group relative to the control group.

Since approximately $50 \%$ of the obese women in our study withdrew, we analyzed the data to determine if the subjects who could not achieve ideal body weight might have a lower initial metabolic rate than those who were successful in achieving ideal body weight, perhaps explaining their failure. The data in Table III indicates that this is not the case. This supports the conclusion that those who have difficulty losing weight do not have a lower RMR or TEE, as well as the conclusion that the successful reduced obese group is not a subgroup with a higher metabolic rate.

The lack of correlation between energy expenditure and the amount of weight regained in 10 women who were reweighed 18-34 mo after completion of the study adds further support to the conclusion that low energy expenditure is not a common cause of obesity. While we cannot discount the possibility that a significant correlation between energy expenditure and weight regain would be found with a much larger group of subjects or with longer followup, the data are consistent with our failure to observe reduced energy expenditure in the reduced obese group and the lack of differences in energy expenditure between successful and unsuccessful subjects. Furthermore, we can state definitively that the reduced obese group is not an unusual group of obese women who succeeded in maintaining their weight near the ideal level. There was no evidence for a deficit in energy expenditure in this subgroup. The mean RMR of this group was nearly identical to the predicted value, and their mean TEE was $215 \mathrm{kcal} / \mathrm{d}$ above the predicted value. Thus a normal or high expenditure does not protect reduced obese subjects from regaining weight.

None of our reduced obese subjects had an abnormally low energy expenditure, as defined by a TEE lower than 2 SD below the predicted value. According to binomial probabilities, we can be $95 \%$ certain, with $n=18$, that $<16 \%$ of all reduced obese women would have a TEE lower than 2 SD below the predicted normal value. Another way to evaluate the data is to ask what deficit in total energy expenditure could realistically lead to an average weight gain of $25 \mathrm{~kg}$, i.e., the average excess weight of the obese subjects who reduced to ideal body weight. Since total energy expenditure rose by $\sim 20 \mathrm{kcal}$ for each $\mathrm{kg}$ of weight when data of all subjects (excluding post-weight loss data) were analyzed, the initial caloric deficit would have to be an average of $500 \mathrm{kcal} / 24 \mathrm{~h}$. In other words, the reduced obese group would need to have an initial average total energy expenditure of only $\sim 1800 \mathrm{kcal} / 24 \mathrm{~h}$ in order to gain $25 \mathrm{~kg}$ if they ate the same amount of food as the control group. The mean energy expenditure of the reduced obese group was over 2400 $\mathrm{kcal} / 24 \mathrm{~h}$. Thus, the data suggest that the original weight gain above ideal body weight in the obese subjects was not caused by low energy expenditure. A third way to evaluate the data is to ask how much weight gain would be expected in the reduced obese subjects if they all had a caloric deficit at the $95 \%$ confidence limits for the difference between the reduced obese and never obese subjects $(-51 \mathrm{kcal} / 24 \mathrm{~h})$. This caloric deficit could lead to a weight gain of only $\sim 3 \mathrm{~kg}$ since at that point the energy deficit would be overcome by the increased energy expenditure associated with being overweight. Thus, assuming no change in physical activity and assuming that the increase in energy expenditure with weight gain in reduced obese subjects follows the cross-sectional data, one could explain only a small percentage of their overweight as being due to decreased energy expenditure.

In conclusion, none of the obese subjects reduced and stabilized at ideal body weight demonstrated abnormally low energy expenditure, and weight regain is not inversely correlated to energy expenditure. Subjects who fail to lose weight do not have a low initial energy expenditure. These studies support the conclusion that in a genetically heterogeneous population, the propensity to become obese or maintain the obese state is not related to a low energy expenditure.

\section{Acknowledgments}

We wish to acknowledge the secretarial assistance of Ms. Sandy Webster and Ms. Sharon Harris.

This work was supported by National Institutes of Health grants DK40816 and RR00044.

\section{References}

1. Van Itallie, T. B. 1985. Health implications of overweight and obesity in the United States. Ann. Intern. Med. 103:983-988.

2. Bray, G. A. 1985. Complications of obesity. Ann. Intern. Med. 103:10521062.

3. Grundy, S. M., and J. P. Barnett. 1990. Metabolic and health complications of obesity. Disease-a-Month. 36:644-696.

4. Bouchard, C. 1991. Current understanding of the etiology of obesity: genetic and nongenetic factors. Am. J. Clin. Nutr. 53:1561S-1565S.

5. Price, R. A., A. J. Stunkard, R. Ness, T. H. Wadden, S. Heska, B. Kanders, and A. Cormillot. 1989. Childhood onset (age $<10)$ obesity has high familial risk. Int. J. of Obes. 14:185-195.

6. Stunkard, A. J., T. I. A. Sorensen, C. Hanis, T. W. Teasdale, R. Chakraborty, W. J. Schull, and F. Schulsinger. 1986. An adoption study of human obesity. N. Engl. J. Med. 314:193-198.

7. Stunkard, A. J., J. R. Harris, N. L. Pedersen, and G. E. McClearn. 1990 The body-mass index of twins who have been reared apart. N. Engl. J. Med. 322:1483-1487.

8. Bouchard, C., A. M. Tremblay, J.-P. Despres, A. Nadeua, P. S. Lupien, G Theriault, J. Dussault, S. Moorjad, S. Pinault, and G. A. Fournier. 1990. The response to long-term overfeeding in identical twins. N. Engl. J. Med. 322:14771482.

9. Bogardus, C., S. Lillioja, E. Ravussin, W. Abbott, J. K. Zawadaki, A. Young, W. C. Knowler, R. Jacobowitz, and P. P. Molt. 1986. Familial dependence of the resting metabolic rate. N. Engl. J. Med. 315:96-100.

10. Bouchard, C., A. Tremblay, A. Nadeau, J. P. Despres, J. P. Thjeriault, G. Bouley, G. Lorties, C. Leblanc, and G. Fournier. 1989. Genetic effect in resting and exercise metabolic rates. Metab. Clin. Exp. 38:364-370.

11. Ravussin, E., S. Lillioja, W. C. Knowler, L. Christin, D. Freymond, W. G. H. Abbott, V. Boyce, B. V. Howard, and C. Bogardus. 1988. Reduced rate of energy expenditure as a risk factor for body-weight gain. $N$. Engl. J. Med. 318:467-472. 
12. Ravussin, E., B. Burnand, and Y. Schultz. 1985. Energy expenditure before and during energy restriction in obese patients. Am. J. Clin. Nutr. 41:753759.

13. Weigle, D. S., K. J. Sande, P.-H. Iverius, E. R. Monsen, and J. D. Brunzell. 1988. Weight loss leads to a marked decrease in nonresting energy expenditure in ambulatory human subjects. Metab. Clin. Exp. 37:930-936.

14. Leibel, R. L., and J. Hirsch. 1984. Diminished energy requirements in reduced-obese patients. Metab. Clin. Exp. 33:164-170.

15. Miller, D. S., and S. Parsonage. 1975. Resistance to slimming adaptation or illusion? Lancet. 1:773-775.

16. Geissler, C. A., D. S. Miller, and M. Shah. 1987. The daily metabolic rate of the post-obese and the lean. Am. J. Clin. Nutr. 45:914-920.

17. Elliot, D. L., L. Goldberg, K. S. Kuehl, and W. M. Bennett. 1989. Sustained depression of the resting metabolic rate after massive weight loss. Am. J. Clin. Nutr. 49:93-96.

18. Shah, M., D. S. Miller, and C. A. Geissler. 1988. Lower metabolic rates of post-obese versus lean women: thermogenesis, basal metabolic rate and genetics. Eur. J. Clin. Nutr. 42:741-752.

19. McNeill, G., S. G. F. Bukkens, D. C. Morrison, and J. S. Smith. 1990. Energy intake and energy expenditure in post-obese women and weight-matched controls. Proc. Nutr. Soc. 49:14. (Abstr.)

20. Welle, S. L., J. M. Amatruda, G. B. Forbes, and D. H. Lockwood. 1984. Resting metabolic rates of obese women after rapid weight loss. J. Clin. Endocrinol. \& Metab. 59:41-44.

21. de Grott, L., A. J. H. van Es, J. M. A. van Raaij, J. E. Vogt, and J. G. A. J. Hautvast. 1990. Energy metabolism of overweight women 1 mo and 1 y after an 8-wk slimming period. Am. J. Clin. Nutr. 51:578-583.

22. James, W. P., M. E. J. Lean, and G. McNeill. 1987. Dietary recommendations after weight loss: how to avoid relapse of obesity. Am. J. Clin. Nutr. 45:1135-1141.

23. Bessard, T., Y. Schutz, and E. Jequier. 1983. Energy expenditure and postprandial thermogenesis in obese women before and after weight loss. $\mathrm{Am}$. $J$. Clin. Nutr. 38:680-693.

24. Dore, C., R. Hesp, D. Wilkins, and J. S. Garrow. 1982. Prediction of energy requirements of obese patients after massive weight loss. Hum. Nutr. Clin. Nutr. 36C:41-48.
25. National Diabetes Data Group. 1957. Classification and diagnosis of diabetes mellitus and other categories of glucose intolerance. Diabetes. 28:10391057.

26. Schoeller, D. A. 1988. Measurement of energy expenditure in free-living humans by using doubly labeled water. $J$. Nutr. 118:1278-1289.

27. Welle, S., G. B. Forbes, M. Statt, R. R. Barnard, and J. M. Amatruda. 1992. Energy expenditure under free-living conditions in normal-weight and overweight women. Am. J. Clin. Nutr. 55:14-21.

28. Welle, S. 1990 . Two-point vs. multipoint sample collection for the analysis of energy expenditure by use of the doubly labeled water method. Am. J. Clin. Nutr. 52:1134-1138.

29. Schoeller, D. A., E. Ravussin, Y. Schultz, K. J. Acheson, P. Baertschi, and E. Jequier. 1986. Energy expenditure by doubly labeled water: validation in humans and proposed calculation. Am. J. Physiol. 250:R823-830.

30. Schoeller, D. A. 1983. Energy expenditure from doubly labeled water: some fundamental considerations in humans. Am. J. Clin. Nutr. 38:999-1005.

31. Welle, S., and K. S. Nair. 1990. Relationship of resting metabolic weight to body composition and protein turnover. Am. J. Physiol. 258:E990-998.

32. Forbes, G. B., F. Schultz, C. Cafarelli, and G. H. Amirhakimi. 1968. Effects of body size on potassium-40 measurement in the whole body counter (tilt-chair technique). Health Phys. 15:435-442.

33. Dixon, W. J. 1983. BMDP Statistical Software. University of California Press, Berkeley, CA.

34. Bouchard, C., R. Savard, J.-P. Despres, A. Tremblay, and C. Leblanc. 1985. Body composition in adopted and biological siblings. Hum. Biol. 57:61-75.

35. Roberts, S. B., J. Savage, W. A. Coward, B. Chen, and A. Lucas. 1988. Energy expenditure and intake in infants born to lean and overweight mothers. $N$. Engl. J. Med. 318:461-466.

36. Griffiths, M., and P. R. Payne. 1976. Energy expenditure in small children of obese and non-obese parents. Nature (Lond.). 260:698-700.

37. de Boer, J. O., A. J. H. van Es, L. A. Roovers, J. M. A. van Raaij, and J. G. A. J. Hautvast. 1986. Adaptation of energy metabolism of overweight women to low-energy intake, studied with whole-body calorimeters. Am. J. Clin. Nutr. 44:585-595.

38. Astrup, A., B. Buemann, N. J. Christensen, and J. Madsen. 1992. 24-hour energy expenditure and sympathetic activity in post-obese women consuming a high-carbohydrate diet. Am. J. Physiol. 262:E282-E288. 